\title{
Application of Vigosky's Social Constructivism Theory on Lecturers' Perspective of Supplemental Instruction Peer Facilitation Model
}

\author{
Luyanda Marhaya \\ Teaching and Learning Centre, University of Fort Hare \\ Email:Imarhaya@ufh.ac.za
}

\section{Doi:10.5901/mjss.2014.v5n11p37}

\section{Abstract}

The study seeks to gather a perspective on the impact of supplemental instruction model as a student enhancement support mechanism from lecturers involved in two modules supported in the programme. This is a qualitative case study design study of a supplemental instruction model used as a student enhancement support mechanism by lecturers in one institution of higher learning in the Eastern Cape Province. Four lecturers, who are currently utilizing this model, which consist of two from each programme involved in the study, have been drawn. These participants have been purposefully selected based on knowledge and utilization of this tool. A narrative approach soliciting their stories through the use of open ended questionnaire is seen as ideal in order to get rich data. Emerging themes were analysed using a thematic approach. The results suggest that there is a general satisfaction on how the academics perceive, experience and what they expect from the programme. The study concludes that all stakeholders could benefit if good relations are maintained. It is recommended that they should be continuous strengthening of relations amongst all stakeholders involved in the programme.

Keywords: Constructivism, Lecturers, Supplemental Instruction, peer facilitation.

\section{Introduction}

Supplemental instruction locates itself to (Vigotsky's, 1978) social constructivism theory as a social participation theory that happens amongst peers in learning activities. Vigotsky defines (1978: 56-57) social constructivism as:

"a sociological theory of knowledge that applies the general philosophical constructivism into social settings, wherein groups construct knowledge for one another, collaboratively creating a small culture of shared artifacts with shared meanings. When one is immersed within a culture of this sort, one is learning all the time about how to be a part of that culture on many levels."

(Vigotsky, 1978) theory maintains that social interaction plays a fundamental role in the development of cognition. Green (in Ladyshewsky and Gadner, 2008) expands on the work of Vigotsky where he refers to 'spaces of influence' where an individual can gain learning through the support of others. This is supported in (Falchikov, 2001) who asserts that the role peers can play in peer learning is to provide 'expert scaffolding' which enables students to achieve to their next level of development.

Furthermore, (Ladyshewsky and Gadner, 2008) posit that social constructivism provides a theoretical underpinning for supplemental instruction model as learning best takes place when it occurs in discourse with peers from within that knowledge community. In addition, (Smith, May and Burke, 2007) highlighted the following points as advantages of the Supplemental Instruction model, and they trace this to the social constructivism theory of (Vigotsky, 1978):

1. Students resent being forced to participate in remedial modules and programmes, and students are more likely to benefit from support programmes that specific target high risk courses rather than high risk students.

2. First-year students are more likely to engage actively in sessions that are student-facilitated rather than those that are facilitated by lecturers.

3. Successful second and third-year students are better equipped than lecturers to help first-year students to become expert students.

Vigotsky's theory of constructivism (1978) is also emphatic in that peer interaction is conducive to cognitive development due to the promotion of critical conflicts. In the same way, ( Ning and Downing, 2010) also point out that when a leaner becomes aware of contradictions in his/ her knowledge base through peer discussion, this triggers a lapse in equilibrium which will cause the leaner to initiate an inquiry orientated problem solving process to a solution. Pursuing this further, the authors argue that the reconstruction of knowledge to propagate understanding is characteristic of constructivist learning where the notion of knowledge is more thorough when it is constructed and reconstructed, and not simply distributed. 


\section{Supplemental Instruction in Context}

Supplemental instruction was developed by Dr. Dean Martin in 1973 at the University of Missouri at Kansas City (UMKC) to increase the performance and retention of students in high risk classes, (Hurley, Jacobs and Gilbert, 2006). The main focus of SI is to guide students in learning appropriate study strategies, such as note taking, graphic organization, question techniques, vocabulary acquisition, and test preparation while also reviewing content material, (Jocobs, Hurley and Gilbert, 2008). Moreover, ( Jacobs et al, 2008) also posit that supplemental instruction sessions are proactive and participatory rather than reactive and passive because they strive to break what is called a dependency cycle or what they call ' learned helplessness'. In the same way, this is epitomised in one of Vogtsky's principles that peer interaction is conducive to cognitive development due to the promotion of critical conflicts.

(Ning and Downing, 2010) describe supplemental instruction as a different type of peer facilitation as it encompasses a certain hierarchy of educational level where a senior student tutors a group of junior students. Consequently, these authors further indicate that the theoretical framework underlying peer assisted learning is constructivism, where tutors take the role of facilitators to help learners process and understand information and construct their own knowledge rather than the role of givers who provide knowledge for student to assimilate. In addition (Jocobs et al, 2008) describe supplemental instruction as having sessions that are regularly scheduled informal reviews in which students compare notes, discuss readings, develop organisational tools, solve problems, and predict test items.

SI programmes are designed to provide and promote a high degree of student interaction and mutual support and to capitalise on the power of group study and the practice of collaborative learning and interaction through peer study groups (Madiope and Ranko-Ramaili, 2013). In conceptualising the supplemental instruction model, Dean Martin also believed in social constructivism, the idea that learning happens best when students construct their own knowledge as peers. As has been mentioned previously, that is the fundamental principle that Vigotsky purports.

SI was implemented at the targeted university in 2005. SI was first introduced in the Faculty of Science \& Agriculture and has since expanded to provide support to students in all Faculties. SI is housed in the Teaching and Learning Centre (TLC) and is a partnership between TLC and the relevant academic departments.

Success in the Supplemental instruction programme lies in the fact that sessions are proactive and participatory rather than reactive and passive, therefore; students take more responsibility for their educational experience than they would in a conventional learning environment where they depend on an authority figure for learning, Ning and Downing ( in Hurley, Jacobs, and Gilbert, 2006). Furthermore, a study conducted at West Virginia School of Nursing by (Harding, 2012) to investigate the effects of supplemental instruction on student success found that out of the 13 students who were previously not successful in the nursing course, only one failed while receiving assistance after supplemental was introduced.

It should be noted though that supplemental instruction is not without certain challenges. (McGuire, 2006: 8-9) mentions three challenges. These are the challenges:

- Many students are reluctant to attend the sessions on a regular basis, opting to attend only before an examination.

- Because supplemental instruction is targeted at high risk, high- enrolment courses, and not simply provided on instructor request, some faculty do not strongly encourage their student to attend sessions regularly.

- Effective supplemental instruction sessions involve extensive discussions among students in the group, with the SI leader serving as a facilitator. As ( McGuire, 2006) posit, many of today's students appear to be much more interested in interacting with computers than interacting with one another learning course content.

Moreover, Huang et al (in Hodgson et al, 2012) believes that unfavourable results such as student dissatisfaction can result when student expectations and staff expectations are misaligned in a poorly designed PASS program.

In light of the above concerns, it is easy to see that central to the success of the supplemental instruction model, is the support system that the university gives.

\section{Academic Departments and Supplemental Instruction Model}

As has been mentioned, academic departments play a vital role in the success of any supplemental programme. Certainly, (Zarisky and Toce, 2008) put it that it is essential to choose faculty who view themselves as 'gate openers' rather than ' gatekeepers' because the former are more likely to support the programme by encouraging students in their class to attend classes.

Furthermore, (Zerger, Unite and Smith, 2006) also believe that supplemental instruction model is built on collaboration with faculty in the development of enhanced curriculum. In the same way, (Marra and Litzinger, maintain 
that the instructor/professor of the SI-targeted course is also a key player in the SI program because while the SI program does ask a faculty member to change the way he/she teaches the SI targeted course, the faculty member must at a minimum agree to the competency of the proposed SI leader (if not have a hand in choosing that leader), agree to have the SI leader sit-in on lectures, and promote the SI sessions during the main lecture session. Following this further, (Madiope and Ranko-Ramaili, 2013) are emphatic in that understanding behind SI is that lecturers through their experience are aware of contents within their modules that have the tendency of being problematic, year-in-year-out, and despite the academic strategies that a lecturer might have practiced to improve students' performance, students continue performing dismally in these parts of the module

However, recent research indicates that much of the literature around supplemental instruction has only thus far focused on students as if they are the only people who are involved with the programme, this is supported by ( Huang, Pepper, Cortese and Rogen, 2013) , wherein they infer that much of the supplemental instruction literature had a focus on the involvement of students ("people to involve") while overlooking the importance of consulting faculty staff, especially teaching academics ("people to consult"). Additionally, (Huang et al, 2013) suggest that to move forward it is equally important to understand the expectations of staff as key stakeholders within the program, especially in the context of university education where academic teaching staff have a high stake in the success or failure of students. Following this further, (Huang et al, 2013) maintain that perceptions of academics can be used to plan and implement more effective PASS programs for faculties. Also, Huang et al (in Longfellow et al. 2008) suggest academic staff may hold "doubtful or hostile" views towards PASS programs due to concerns over academic quality of PASS sessions and unhelpful or inappropriate re-teaching, which potentially leads to poorer performance for PASS participants. Consequently (Hurley, Jacobs and Gilbert, 2006) also posit that the faculty's role has become more and more critical as a team approach is best in producing positive results. Following this further, ( Hurley et al, 2006) believe that faculty must be supportive of the supplemental instruction model and understand how the peer- led sessions can help students learn more effectively.

Clearly, then- the success of supplemental instruction as a peer facilitator programme is dependent on the support of academics involved in the programme. Therefore the objective of this paper is to gather how academics supported by the programme view or perceive it, and its impact thereof.

\section{Research Design}

The study is located in the interpretivism paradigm because it seeks to gather perspectives from the lecturers involved in the two programmes at a university of higher learning. Mack ( 2010) purports that the role of the scientist in the interpretivist paradigm is to, understand, explain, and demystify social reality through the eyes of different participants". I used the interpritivism paradigm to understand and explain the impact of the supplemental peer facilitation model on student success.

Through interpritivism paradigm, a qualitative case study research has been employed. Yin, (2003) posits that a case study design should be considered when: (a) the focus of the study is to answer "how" and "why" questions; (b) you cannot manipulate the behaviour of those involved in the study; (c) you want to cover contextual conditions because you believe they are relevant to the phenomenon under study. The case studies in this paper are the lecturers involved in the two programmes. A qualitative research approach will be employed for the purposes of this study, (Denzin and Lincoln, 2000) assert that the strength of a qualitative research is its ability to provide complex textual descriptions of how people experience a given research issue. They further suggest that it provides information about the human side of an issuethat is, the often contradictory behaviours, beliefs, opinions, emotions and relationships of individuals. This approach therefore is deemed as ideal as the objective is to get the participants' perspective on the impact of the supplemental instruction peer facilitation model.

The population sample consists of only the four lecturers involved in the two programmes. The participants have been chosen purposefully as the intention is to gather data from people who have knowledge, and thus utilise the model in the two programmes. According to Bernad (2000) purposive sampling technique, also called judgment sampling, is the deliberate choice of an informant due to the qualities the informant possesses. It is a non-random technique that does not need underlying theories or a set number of informants. Simply put, the researcher decides what needs to be known and sets out to find people who can and are willing to provide the information by virtue of knowledge or experience. Admittedly, the lecturers were therefore deemed as ideal participants to provide rich data as they have been involved in the programmes.

Data has been collected using an open- ended questionnaire that will be evenly distributed to all participants via email. (Tuckman, 1978) affirms that questionnaires are used by researchers to convert information directly by people into data. Furthermore, the author believes that by providing access to what is inside somebody's mind, the approach makes 
it possible to measure what this person knows, likes and disliked and what he thinks. The instrument is therefore deemed ideal as the idea is to get their perceptions about supplemental programme. The idea is really to give an account of what they know, think, like and dislike about the programme through a set the questions that will be distributed.

Responses were received from all participants that were targeted through e-mail. Central themes emerging from their responses have been analysed and discussed. Respondents have not been mentioned by name rather the use of academic 1 to 4 will be used.

\section{Results}

\subsection{Perceptions of the SI programme}

The general sentiment is that the academics involved seem to understand what the programme is trying to achieve. Also, their perception stems from the understanding that SI leaders are senior students who are chosen amongst many applicants based on particular criteria that the TLC uses, as can be observed in the following statements:

Academic 1: It is a student at a higher level of study helping other students at first year level of study. SI leaders use certain strategies that are student focused.

Academic 2: I see the SI programme as being a method to assist students to improve their proficiency in a subject. In particular where students may have difficulty in understanding a certain section of the work they have assistance available.

However, the academics also raised serious concerns about the type of SI leaders that are chosen. The general feeling is that students who become part of SI should have excelled in that particular module so that they are not found wanting in sessions, this can be observed in these statements.

Academic 1: The SI leader must have a good understanding of the course in which he/she is helping.

Academic 3: The SI leaders are trained on how to deal with students; however, I believe that they also need to be trained on the specific subject they will be dealing with, since they must be good in the content they will be presenting to students.

Admittedly, the academics hold a positive perception of the SI programme although they felt that SI leaders should be well versed with the module. They did not indicate any instances thou that there were some SI leaders who were performing below par when it comes to content knowledge. The points they raise augers well with the TLC procedures for selecting SI leaders. A mark per pass percentage of a selected module is one of the criterions that students have to meet when they apply. Currently, students must have obtained more than $60 \%$ throughout the years they enrol for, in that particular module. Furthermore, academics are also involved in the recruitment process since they have dealt with the students who apply in their classes. In fact, a recommendation should come from them for a student to be selected a SI leader. With all those steps, it is rather rare that a below average student in term of performance in that area could be selected.

\subsection{Experiences of the SI programme}

The resounding theme that emerged from all participants was an overall satisfaction with the assistance that the SI leaders were providing. Some academics indicated that they were not aware of the SI programme before they joined the university but have since embraced it as they can see the impact it has. The general sentiment was that on the students who attended, there was an indication of improvement, as can be observed from the following responses:

Academic 1: The programme has been helping the students, especially with practical modules; the students who were very reserved in class can now participate because they are given platform where they can engage in discussions with fellow students.

Academic 2: Most of the people I have worked with who are either SI or former SI leaders have shown good leadership skills and are reliable.

Academic 3: Students who actively participate in class do well in the course.

Although some did not indicate whether they were basing their answers on research, they still felt that there was evidence of improvement. However, one did indicate that he does not base his answer on empirical evidence but he does see the improvement, as can be observed: "I do not have empirical evidence but I have seen students who have had difficulty with a section of work improve after being assisted by a SI leader.

Furthermore, this question has given the researcher an indication that the lecturers involved do understand the role of an SI leader, as can be observed here:

Academic 2: They seem to understand students and they always have patience for the students. I have noticed that sometimes, my SI leaders makes arrangements with students for extra sessions where they will be solving problems 
and discussing previous question especially when students are about to write tests.

Academic 4: Students are also able to ask questions in my classes now. Previously when there were no SI leaders, you can tell that first year students are usually very shy, I am experiencing a bit of active participation, I am sure it is all the discussion that usually happens in those SI sessions.

This might due to the fact that TLC Consultants hold one on one meeting with each lecturer responsible in that particular module. The intention is to explain what the programme entails, and the cooperation thereof in terms and conditions between TLC and academic departments. During meetings, academics are told what the programme is, what purpose it serves, and the intended outcomes thereof.

\subsection{Expectations of the SI programme:}

Emerging theme in this particular question was that SI leaders are facilitators, not teachers; therefore, they should refrain from teaching them. As can be observed here:

Academic 1: If students have difficulty in one of the concepts discussed in class I am expecting the leader to be able to explain that concepts to students but not to teach them.

Academic 3: I am expecting SI leaders to help students in areas where they are experiencing difficulties, this is important because their sessions only last for 45 minutes and so should focus on important areas where I was also not able to dwell much.

Academic 4: I am expecting SI leaders to be able to assist students and not to contradict them. In other for them not to contradict students, I am expecting that they must meet with the lecturer in charge to discuss the concepts where they are facing difficulties.

Also, it was interesting to note that they also expect them to deal with other issues that are not related to academic as they feel that social issues that students face directly affects their academic work, this can be observed here:

Academic 4: They must make sure that their junior students understand university life, and cope socially. They must be able to identify the students who might have problems socially and inform the lecturer.

Academic 1: Lastly, I am expecting the leader to able to guide students in other social issues as well as they are more closer to them, and in turn students turn to open up more to their peers.

This is an important point to note and hopefully will be addressed with the SI leaders. It should be noted thou that as much as SI leaders are close to students, they are only limited to academic related activities. The risk of including this aspect in the programme would be a situation where more and more students start consulting about their personal problems to the SI leader. This could lead to a situation where the SI leader is found wanting as they are not trained to deal with personal issues of students

\section{Discussion}

The results of the study have assisted in helping the researcher understand the perceptions that academics hold about the programme. The central reality is that, there is not much that has been written about how academics perceive the programme in international and local literature.

The results indicate that academics hold a positive perception towards the supplemental instruction. Academics seem to embrace the supplemental instruction programme as it assists in developing first year students. This is in contradiction to (Longfellow et al, 2008) assertion that some academics tend to hold hostile views of the programme. However, academics did also indicate that an SI leader involved in the programme has to be competent in the module. This is consistent with (Madiope and Ranko-Ramaili, 2013) views on that, lecturers are often aware of the challenging parts of the module, and therefore will guide the SI leader to focus on those particular areas. It is of great value when the SI leaders are well versed and competent in the module. A general sentiment was that academics are quite satisfied with the level of competency; some cited the regular training that is given to SI leaders.

Academics were also able to share positive experiences about the programme. The positive nature within which they were able to respond indicates that they do understand what the programme intends to achieve. Academics were able to indicate that the students who had attended SI session improve their communication skills compared to those who did not, although this is merely an observation, and not empirical. This argues well with (Hurly et al, 2006) description of supplemental instruction when they assert that success in the Supplemental Instruction programme lies in the fact that sessions are proactive and participatory rather than reactive and passive, therefore; students take more responsibility for their educational experience than they would in a conventional learning environment where they depend on an authority figure for learning.

Academics seem to have varying views in what they expected the SI to do. However, there is a general sentiment 
that they expected SI leaders to help the first year students outside their sessions. This means that they also have to assist in social related issues. However, there was some level of expectation that I am not sure the SI leaders will be able to meet. The general sentiment was that, since SI leaders are more comfortable talking about their personal issues to them, they could be in a position to identify those students and refer those to them. The other resounding theme was the fact that they seemed to know the impact the programme can make in these students

Lastly, the challenges mentioned by (McGuire, 2006) could not be established at any level of the research.

\section{Conclusion}

The study allowed the researcher an opportunity to delve deep into the perceptions that academics have about the programme. The study has argued that without the cooperation of academics in the Supplemental Instruction programme, success is unlikely to be realised. Also, the study has discussed how beneficial the supplemental instruction is, according to the theoretical framework of Vigotsky on peer facilitation. The findings therefore can assist in strengthening the relationship of the Teaching and Learning Centre with the supported faculties.

\section{Recommendation}

It is recommended that there should be further strengthening between the Teaching and Learning Centre and faculties. The consultants at the centre should maintain the cordial relations shared between the centre and faculties. Academics seemed to understand the supplemental instruction programme; this will go a long way in contributing to the success of the programme.

It was also worth noting that academics expect SI leaders to go beyond their call of duty in assisting students outside their sessions. This recommendation will be tabled at the Teaching and Learning Centre meeting, to ascertain if any capacity building mechanisms could be devised so that they are able to assist. Furthermore, more initiatives should be done to capacitate student in terms of being well versed with content. This will also be inculcated into training. Currently, SI leaders attend lecture sessions on modules in which they are involved, in addition, hold meetings with lecturers to discuss module sections that are deemed to be challenging.

\section{References}

Bernard, H. (2000). Social Research Methods: Qualitative Research and Quantitative approaches. Thousand Oaks: Sage Publications.

Garder, P., \& Ladyshewisky, K. (2008). Peer assisted learning and blogging: A strategy to promote reflective practice during clinical fieldwork. Australian Journal of Educational Technology , 24 (3), 241-257.

Hodgson, Y., Bearman, M., \& Shneider-Kolysky, M. (2012). Lessons leraned in implementing peer assisted learning. International Journal of Innovation in Science and Mathematics Foundation, 20 (3), 292-302.

Huang, T., Pepper, M., Cortese, L., \& Rogan, S. (2013). Faculty and academic staff perceptions, experiences and expectations of the Pass programme: A case study. Journal of Peer Learning , 6 (1), 118-132.

Hurley, M., Jacobs, G., \& Gilbert, M. (2006). The Basic SI model. In M. Stone, \& G. Jacobs (Eds.), Supplemental Instruction: New Visions for Empowering Student Learning (pp. 11-22). San Fransico: Wiley Periodicals, Inc.

Jacobs, G., Hurley, M., \& Unite, C. (2008). How Learning theory creates a foundation for SI leader training. Australasian Journal of Peer Learning (1), 6-12.

Longfelloow, E., May, S., Burke, L., \& Marks-Maran, D. (2008). They had a way of helping that actually helped: A case study of a peer- assisted learning. Teaching in Higher Education, 13 (11), 93-105.

Mack, L. (2010). The Philosophical Underpinnings of Educational Research. Polyglossia, 19.

Madiope, M., \& Ranko-Ramaili, M. (2013). The place of podcasting in open distance learning in teacher education in open distancelearning environments. In R. McBride, \& M. Searson (Ed.), Proccedings of Society for Information Technology and Teacher Education International Conference (pp. 743-751). Chesapeake: VA: AACE.

McGuire, S. (2006). The Impact of Supplemental Instruction on Teaching Students How To Learn. In M. Stone, \& G. Jacobs (Eds.), Supplemental Instruction: New Visions for Empowering tudent Learning (pp. 3- 10). San Francisco: Wiley Periodicals, Inc.

Ning, H., \& Downing, K. (2010). The impact of supplemental instruction on learning competence and academic perfomance. Studies in Higher Education , $35(8), 921-939$.

NK, D., \& Lincoln, Y. (2000). Handbook of Qualitative Research. London: Sage Publications.

Smith, J., May, S., \& Burke, L. (2007). Peer assisted learning: A case study into the value to student mentors and mentees. Practice and Evidence of the Scholarship of Teaching and Learning in Higher Education , 2 (2), 80- 109.

Tuckman, B. (1978). Conducting educational research (2nd ed.). London: Harcourt Brace Jovanovich.

Vigotsky, L. (1978). Mind in Society: The Development of Higher Education Psychological Processes. Cambridge: Havard University Press.

Yin, R. (2003). Case Study Research: Desing and methods (3rd ed.). Thousand Oaks: CA: Sage.

Zaritsky, J., \& Toce, A. (2006). Supplemental Instruction at a Community College. In M. Stone, \& G. Jacobs (Eds.), Supplemental Instruction: New Visions for Empowering Student Learning (pp. 23- 42). San Francisco: Wiley Periodicals Inc.

Zerger, S., Clark- Unite, C., \& Smith, L. (2006). How Supplemental Instruction Benefits Faculty. In M. Stone, \& G. Jacobs, Supplemental Instruction: New Visions for Empowering Student Learnig (pp. 63-72). San Francisco: Wiley Periodicals Inc. 